\title{
Efficacy and Safety of Anlotinib for Elderly Patients with Previously Treated Extensive-Stage SCLC and the Prognostic Significance of Common Adverse Reactions
}

This article was published in the following Dove Press journal:

Cancer Management and Research

\section{Peng-Fei Song \\ Ning $X u$ \\ Qin Li}

Department of Respiratory and Critical Care Medicine, The First People's Hospital of Lian Yun Gang, Lian Yun Gang 222000, Jiangsu, People's Republic of China
Correspondence: Qin Li

Department of Respiratory and Critica Care Medicine, The First People's

Hospital of Lian Yun Gang, 182 North

Tongguan Road, Lian Yun Gang 222000,

Jiangsu, People's Republic of China

Tel $+86 \quad 18961325376$

Email I896I325376@I89.cn
Background: This study was to investigate the efficacy and safety of anlotinib for elderly patients with previously treated extensive-stage small cell lung cancer (ES-SCLC) and the prognostic significance of common adverse reactions.

Patients and Methods: A total of 79 elderly patients ( $\geq 60$ years) with ES-SCLC who failed after at least two lines of previous systemic therapy were included. Baseline characteristics of the patients were collected. Follow-up was conducted regularly. Adverse reactions were documented. Survival curves were drawn using Kaplan-Meier method. Univariate analysis was assessed using log rank test, and multivariate analysis was adjusted by Cox regression analysis. Additionally, the prognostic significance of common adverse reactions was performed.

Results: All of the 79 patients were available for evaluation of efficacy. Partial response (PR) was observed in 7 patients, stable disease (SD) was noted in 48 patients and progressive disease (PD) was confirmed in 24 patients. Consequently, the objective response rate (ORR) was $8.9 \%$ and disease control rate (DCR) was $69.6 \%$. The median progression-free survival (PFS) of the 79 elderly patients with ES-SCLC was 3.0 months [95\% confidence interval (CI): 2.02-3.98]. The median overall survival (OS) was 7.1 months (95\% CI: 5.07-9.13). Safety profile demonstrated that the relatively common adverse reactions of the elderly patients with ES-SCLC receiving anlotinib treatment were hypertension (40.5\%), hand-foot syndrome (HFS, 31.6\%), diarrhea (27.8\%), decreased appetite $(20.3 \%)$, fatigue $(17.7 \%)$ and weight loss $(17.7 \%)$. Interestingly, the prognostic significance of common adverse reactions indicated that the median PFS of patients with hypertension and without hypertension was 4.35 and 2.95 months, respectively $(P=0.01)$, and the median PFS of patients with HFS and without HFS was 4.20 and 2.95 months, respectively $(P=0.03)$.

Conclusion: The preliminary efficacy and safety of anlotinib in the treatment for elderly patients with previously treated ES-SCLC was satisfactory, and patients with hypertension and hand-foot syndrome might confer superior prognosis.

Keywords: elderly small cell lung cancer, anlotinib, efficacy, safety, biomarker

\section{Introduction}

Lung cancer is the most common malignant tumor both in China and worldwide. ${ }^{1}$ Currently, it is estimated that there are approximately 0.73 million new cases and 0.61 million new deaths in China annually. ${ }^{2}$ Small-cell lung cancer (SCLC) is a highly aggressive and lethal malignancy and accounts for approximately $15 \%$ 
of the total number of lung cancers. ${ }^{3}$ Most patients relapsed owing to the emergence of drug-resistant tumor after the successful induction therapy. ${ }^{4}$ Despite the fact that diagnostic techniques were developed, remarkably, approximately $70 \%$ of patients were diagnosed with extensive-stage SCLC (ES-SCLC) with poor prognosis. ${ }^{5}$ Furthermore, no significant breakthrough of the treatment strategy for ES-SCLC was observed in the past 30 years. ${ }^{6}$ Although the regimen of platinum combined with etoposide exhibited superior overall response as the standard first-line treatment, the majority of patients with ES-SCLC relapsed after a short period of response. ${ }^{7}$ The efficacy of routine single-agent chemotherapy as second-line treatment were limited clinically. However, it was noteworthy that immunotherapy demonstrated significant benefit for patients with malignant tumors recently. Pembrolizumab and nivolumab were licensed as third-line setting for patients with ES-SCLC who failed the first- or secondline treatment in the last three years. ${ }^{8,9}$

Angiogenesis is a complex process that plays important roles in tumor growth and metastasis. ${ }^{10}$ Previous research suggested that approximately $80 \%$ of tissues in SCLC were positive of VEGF expression and the VEGF level was an independent prognostic factor in SCLC. ${ }^{11}$ Recent years witnessed that antiangiogenic drugs demonstrated superior anticancer activity in SCLC. ${ }^{12}$ Bevacizumab exhibited improved progression-free survival (PFS) as first line treatment for patients with ES-SCLC in a phase ш clinical trial. ${ }^{13}$ With regard to antiangiogenic small molecule tyrosine kinase inhibitor (TKI), sunitinib, vandetanib, sorafenib, pazopanib and apatinib were investigated as second-line or subsequent-line therapy in clinical trials previously. Unfortunately, efficacy of the TKIs remained dismal and they failed to show clinical benefits for patients with SCLC. ${ }^{14}$ However, anlotinib demonstrated improved PFS and OS significantly in ALTER1202 clinical trial for patients with ES-SCLC as a novel oral multi-target TKI with inhibition of VEGFR1-3, FGFR1-4, PDGFR $\alpha-\beta$, c-Kit and Ret. ${ }^{15}$ Consequently, anlotinib was licensed as the standard third-line regimen for patients with ES-SCLC by the China State Food and Drug Administration (cFDA) in 2019 .

However, to the best of our knowledge, approximately $90 \%$ of patients with SCLC were elderly. ${ }^{16}$ Given that strict age eligibility criteria were set in most clinical trials, relatively rare medical evidence was available regarding the third- and subsequent-line treatment in elderly patients with ES-SCLC clinically. The age of patients in the studies of anlotinib ranged from 31 to 71 with the median of 57 years. ${ }^{15}$ Another phase II study of anlotinib in 45 patients with relapsed SCLC recruited $69 \%$ patients who were under 65 years. ${ }^{17}$ In terms of the studies of pembrolizumab, the age of patients enrolled in Keynote 028 and Keynote 158 ranged from 24 to 84 with the median of 62 years and those of age $\geq 65$ years only accounted for $39.8 \%{ }^{18}$ In consequence, clinical evidence regarding the efficacy and safety for the subsequent-line regimens in elderly patients with ES-SCLC was absent and insufficient.

Furthermore, the objective response rate (ORR) of antiangiogenic targeted drugs were relatively low. In the treatment for ES-SCLC, the ORR of sunitinib, sorafenib, apatinib and anlotinib monotherapy were $0.0 \%, 6.0 \%$, $17.5 \%$ and $4.9 \%$, respectively. ${ }^{19,20}$ Results of these studies indicated that great individual difference was observed regarding the efficacy of antiangiogenic TKIs clinically. Therefore, the investigation of biomarkers which could predict the efficacy of patients who were treated with anlotinib was necessary. ${ }^{21}$

The aim of the present study was to investigate the efficacy and safety of anlotinib for elderly patients with previously treated ES-SCLC and the prognostic significance of common adverse reactions.

\section{Patients and Methods Study Design and Patient Enrollment}

The present study was designed as a real-world retrospective analysis. Patients with ES-SCLC who failed after at least two lines of previous therapy in the Department of Respiratory and Critical Care Medicine of the First People's Hospital of Lian Yun Gang from June 2018 to March 2020 participated in this study. The eligibility criteria were as follows: (a) histologically or cytologically confirmed SCLC; (b) elderly patients with age of $\geq 60$ years; (c) Eastern Cooperative Oncology Group (ECOG) performance status $\leq 2$; (d) anlotinib was administrated for patients who failed after at least two lines of systemic chemotherapy regimens previously. Both patients who relapsed more than 3 months after the completion of first-line chemotherapy (platinum-sensitive) and patients who relapsed within 3 months after the completion of first-line chemotherapy or during chemotherapy (platinum-resistant) were included; (e) at least one measurable target lesion according to response evaluation criteria in solid tumors (RECIST 1.1); ${ }^{22}$ and (f) adequate renal, hepatic and hematopoietic function for patients to receive anlotinib therapy. Key exclusion criteria included: (a) previous exposure to 
anlotinib (however, pervious bevacizumab exposure was permitted); (b) newly diagnostic or untreated central nervous system metastases; (c) concomitant with other tumors or serious diseases based on the decision of the investigator; and (d) absence of the data for efficacy evaluation or followup information. The flow chart of this retrospective study is illustrated in Figure 1. Eventually, a total of 79 elderly patients with ES-SCLC were enrolled. The primary endpoint was PFS, the secondary endpoint was ORR, disease control rate (DCR), overall survival (OS), safety profile and the prognostic significance of common adverse reactions induced by anlotinib. This study was approved by the ethics committee of the First People's Hospital of Lian Yun Gang. Informed consent was signed by each enrolled patient in accordance with the recommendations of the Declaration of Helsinki.

\section{Study Procedures}

All of the patients were treated with anlotinib (anlotinib administrated for 14 days, discontinued for 7 days and repeated every 21 days) at an initial dosage of $12 \mathrm{mg}$ before breakfast with warm water. Dosage reduction to either $10 \mathrm{mg}$ or $8 \mathrm{mg}$ was permitted according to the toxicity during the treatment. Treatment was suspended when life-threatening adverse reactions occurred. Patients continued the treatment until disease progression or intolerable adverse reactions.

\section{Study Assessments and Follow-Up Protocol}

The therapeutic response was evaluated according to RECIST version 1.1 criteria by investigator assessment using the chest computed tomography (CT) scans or nuclear magnetic resonance imaging (MRI) at baseline and during anlotinib treatment. Change of target lesions was assessed every two cycles or based on the actual situation when the clinical symptoms of patients worsened. The best overall response of each enrolled patient was recorded during anlotinib treatment. Furthermore, adverse reactions during treatment were documented using Common Terminology Criteria for Adverse Events (CTCAE) version 4.03 criteria to describe toxicity profile that might be drug-related. ${ }^{23}$ The prognostic significance of common adverse reactions was performed and analyzed. For this analysis, hypertension was defined as either new-onset hypertension or worsening grade (CTCAE v4.03) from baseline in patients with a history of hypertension using $\mathrm{AE}$ data and actual blood pressure

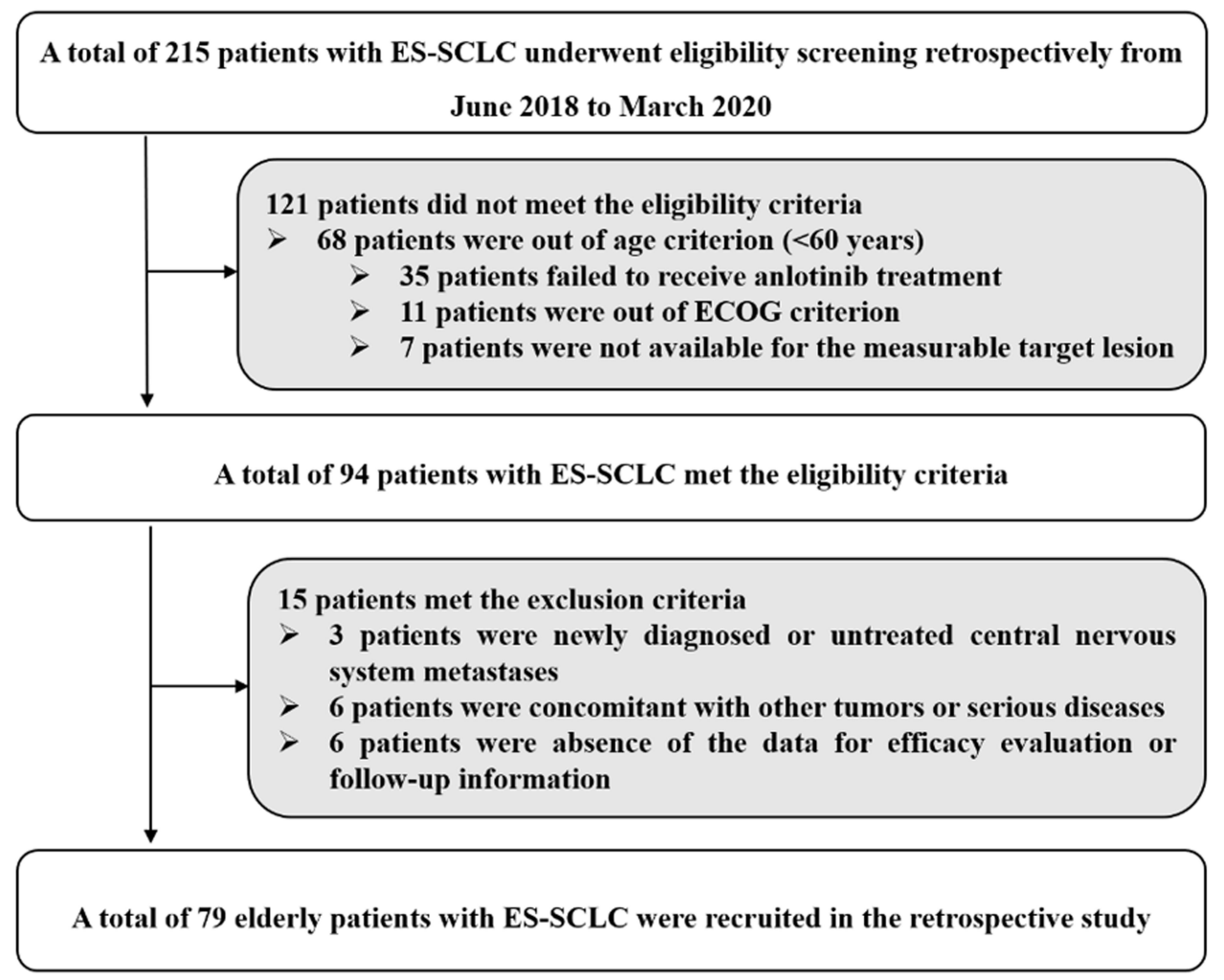

Figure I The flow chart of the retrospective study of anlotinib in the treatment for elderly patients with previously treated extensive-stage small cell lung cancer. 
measurements. For preexisting hypertension, any increase in drug dosage or initiation of a new antihypertensive agent was denoted as grade 3 . $^{24}$

Initial follow-up was performed in the hospital, where baseline characteristics and adverse reactions and the date of disease progression of each patient could be clearly obtained through the electronic medical record system. The subsequent follow-up was performed through mobile phone and progression or death status was mainly obtained. The last follow-up date of this study was June 25, 2020.

\section{Statistical Analysis}

ORR was calculated using the rate of complete response (CR) plus partial response (PR). DCR was calculated using the rate of CR plus PR and stable disease (SD). Variables were statistically analyzed using SPSS version 25.0 (IBM, USA). The PFS was defined as the duration from the date of anlotinib treatment to disease progression or death, whichever occurred first. OS was defined as the duration from the date of anlotinib treatment to death of the patient from any cause. ${ }^{17}$ For those without progression or death events by the end of the study follow-up, survival end points were censored at the date of last follow-up.

Statistical difference of proportion variables and continuous variables according to common adverse reactions status was analyzed using the chi-square test and the Mann-Whitney U nonparametric test, respectively. The primary analysis was performed on PFS. Kaplan-Meier curves were drawn using Stata version 14.0 to compare the differences in PFS according to common adverse reactions status. Survival difference was calculated using log rank test. Cox regression analysis was carried out for PFS in multivariable analysis. Backward-selection procedure was used to adjust the potential confounding covariates. Statistical significance was accepted when $P<0.05$.

\section{Results}

\section{Baseline Characteristics of the 79 Elderly Patients with ES-SCLC}

The baseline characteristics of the 79 elderly patients with ESSCLC is shown in Table 1. The median age of the patients was 71 years (range: $60-83$ years). A total of 56 patients were male (70.9\%). Patients with ECOG $0-1$ score were observed in 42 cases $(53.2 \%)$. Nonsmoker and former smoker/smoker were noted in 11 and 68 patients, respectively. Regarding the relapse type of first-line regimen, platinum-sensitive and platinum-resistant were reported in 38 and 35 patients, respectively. However, 6 patients were not available for the assessment of relapse type. Lines of previous treatment with 2 and $\geq 3$ was observed in 43 and 36 patients, respectively. A total of 53 patients $(67.1 \%)$ received radiotherapy previously. Additionally, 11 patients $(13.9 \%)$ were administrated with targeted drugs previously. Interestingly, 10 patients received immunotherapy previously.

In addition, patients with hypertension and hand-foot syndrome (HFS) were observed in 32 cases (40.5\%) and 25 cases $(31.6 \%)$, respectively. As illustrated in Table 1, baseline characteristics of patients with hypertension and HFS were comparable with those of patients with nonhypertension and non-HFS $(P>0.05)$.

\section{Efficacy of the 79 Elderly Patients with ES-SCLC Who Received Anlotinib}

\section{Therapy}

All of the 79 elderly patients with ES-SCLC were available for efficacy assessment. As described in the method section, the best overall response for target lesions of each enrolled patient was illustrated. Efficacy of anlotinib included CR in 0 patients, $\mathrm{PR}$ in 7 patients, SD in 48 patients and PD in 24 patients. Therefore, the ORR was $8.9 \%$, disease control rate (DCR) was $69.6 \%$. Waterfall plot for the best percentage change in target lesion of the 79 elderly patients with ESSCLC is illustrated in Figure 2. Additionally, the CT scan of the changes for primary target lesions of one patient with SCLC after 2 cycles of treatment with anlotinib is shown in Figure 3 . The treatment with anlotinib was obviouslyeffective and target lesion reduced significantly.

Besides, the median follow-up time for all of the patients was 7.0 months (follow-up range: 0.3-20.0 months). As shown in Figure 4, the median PFS of the 79 elderly patients with ES-SCLC who received anlotinib monotherapy was 3.0 months [95\% confidence interval (CI): 2.02-3.98].

Univariate analysis investigated the median PFS according to different baseline characteristic subgroups. As illustrated in Table 2, only ECOG score was significantly associated with PFS in univariate analysis, which exhibited that the median PFS of patients with ECOG 0-1 score was longer than that of patients with the 2 score (4.1 vs 2.2 months, $P=0.019$ ). Additionally, it should be noted that patients who were platinum-sensitive for first-line chemotherapy had a trend for superior PFS compared with patients who were platinum-resistant, although the difference was not statistically significant (3.9 vs 2.5 months, $P=0.095$ ). 
Table I Baseline characteristics of the 79 elderly patients with ES-SCLC according to hypertension and HFS status

\begin{tabular}{|c|c|c|c|c|c|c|c|}
\hline \multirow[t]{2}{*}{ Characteristics } & \multirow{2}{*}{$\begin{array}{l}\text { Total } \\
(\mathrm{N}=79, \%)\end{array}$} & \multicolumn{2}{|c|}{ Hypertension Status } & \multirow[t]{2}{*}{$P$} & \multicolumn{2}{|c|}{ HFS Status } & \multirow[t]{2}{*}{$P$} \\
\hline & & $\begin{array}{l}\text { Hypertension } \\
(\mathrm{N}=32)\end{array}$ & $\begin{array}{l}\text { Non-Hypertension } \\
(\mathrm{N}=47)\end{array}$ & & $\begin{array}{l}\text { HFS } \\
(N=25)\end{array}$ & $\begin{array}{l}\text { Non-HFS } \\
(N=54)\end{array}$ & \\
\hline $\begin{array}{l}\text { Age (year) } \\
\text { Median (range) }\end{array}$ & 71 (60-83) & 70 (60-79) & $7 \mid(60-83)$ & 0.521 & $69(60-80)$ & $7 \mid(60-83)$ & 0.415 \\
\hline $\begin{array}{l}\text { Gender } \\
\text { Male } \\
\text { Female }\end{array}$ & $\begin{array}{l}56(70.9) \\
23(29.1)\end{array}$ & $\begin{array}{l}21(65.6) \\
\text { II }(34.4)\end{array}$ & $\begin{array}{l}35(74.5) \\
12(25.5)\end{array}$ & 0.396 & $\begin{array}{l}17(68.0) \\
8(32.0)\end{array}$ & $\begin{array}{l}39(72.2) \\
15(27.8)\end{array}$ & 0.701 \\
\hline $\begin{array}{l}\text { ECOG score } \\
0-1 \\
2\end{array}$ & $\begin{array}{l}42(53.2) \\
37(46.8)\end{array}$ & $\begin{array}{l}18(56.3) \\
14(43.8)\end{array}$ & $\begin{array}{l}24(51.1) \\
23(48.9)\end{array}$ & 0.650 & $\begin{array}{l}\text { I4 (56.0) } \\
\text { II (44.0) }\end{array}$ & $\begin{array}{l}28(51.9) \\
26(48.1)\end{array}$ & 0.731 \\
\hline $\begin{array}{l}\text { Smoking status } \\
\text { Nonsmoker } \\
\text { Former smoker/smoker }\end{array}$ & $\begin{array}{l}\text { II (13.9) } \\
68(86.1)\end{array}$ & $\begin{array}{l}5(15.6) \\
27(84.4)\end{array}$ & $\begin{array}{l}6(12.8) \\
4 \mid(87.2)\end{array}$ & 0.719 & $\begin{array}{l}4(16.0) \\
21(84.0)\end{array}$ & $\begin{array}{l}7(13.0) \\
47(87.0)\end{array}$ & 0717 \\
\hline $\begin{array}{l}\text { Relapse type of first-line } \\
\text { regimen } \\
\text { Platinum-sensitive } \\
\text { Platinum-resistant } \\
\text { NA }\end{array}$ & $\begin{array}{l}38(48.1) \\
35(44.3) \\
6(7.6)\end{array}$ & $\begin{array}{l}16(50.0) \\
14(43.8) \\
2(6.2)\end{array}$ & $\begin{array}{l}22(46.8) \\
21(44.7) \\
4(8.5)\end{array}$ & 0.855 & $\begin{array}{l}12(48.0) \\
11(44.0) \\
2(8.0)\end{array}$ & $\begin{array}{l}26(48.1) \\
24(44.4) \\
4(7.5)\end{array}$ & 0.996 \\
\hline $\begin{array}{l}\text { Lines of previous treatment } \\
\quad 2 \\
\quad \geq 3\end{array}$ & $\begin{array}{l}43(54.4) \\
36(45.6)\end{array}$ & $\begin{array}{l}17(53.1) \\
15(46.9)\end{array}$ & $\begin{array}{l}26(55.3) \\
21(44.7)\end{array}$ & 0.848 & $\begin{array}{l}\text { I4 (56.0) } \\
\text { II (44.0) }\end{array}$ & $\begin{array}{l}29(53.7) \\
25(46.3)\end{array}$ & 0.849 \\
\hline $\begin{array}{l}\text { History of previous } \\
\text { radiotherapy } \\
\text { Yes } \\
\text { No }\end{array}$ & $\begin{array}{l}53(67.1) \\
26(32.9)\end{array}$ & $\begin{array}{l}22(68.8) \\
10(31.3)\end{array}$ & $\begin{array}{l}31(66.0) \\
16(34.0)\end{array}$ & 0.795 & $\begin{array}{l}17(68.0) \\
8(32.0)\end{array}$ & $\begin{array}{l}36(66.7) \\
18(33.3)\end{array}$ & 0.907 \\
\hline $\begin{array}{l}\text { History of targeted drugs } \\
\text { therapy } \\
\text { Yes } \\
\text { No }\end{array}$ & $\begin{array}{l}11(13.9) \\
68(86.1)\end{array}$ & $\begin{array}{l}4(12.5) \\
28(87.5)\end{array}$ & $\begin{array}{l}7(14.9) \\
40(85.1)\end{array}$ & 0.763 & $\begin{array}{l}4(16.0) \\
21(84.0)\end{array}$ & $\begin{array}{l}7(13.0) \\
47(87.0)\end{array}$ & 0.717 \\
\hline $\begin{array}{l}\text { History of immunotherapy } \\
\text { Yes } \\
\text { No }\end{array}$ & $\begin{array}{l}10(12.7) \\
69(87.3)\end{array}$ & $\begin{array}{l}4(12.5) \\
28(87.5)\end{array}$ & $\begin{array}{l}6(12.8) \\
4 \mid(87.2)\end{array}$ & 0.972 & $\begin{array}{l}3(12.0) \\
22(88.0)\end{array}$ & $\begin{array}{l}7(13.0) \\
47(87.0)\end{array}$ & 0.905 \\
\hline
\end{tabular}

Abbreviations: ES-SCLC, extensive-stage small cell lung cancer; HFS, hand-foot syndrome; ECOG, Eastern Cooperative Oncology Group; NA, not available.

Furthermore, OS was also assessed in this study. As illustrated in Figure 4, the median OS of the 79 elderly patients with ES-SCLC who received anlotinib monotherapy was 7.1 months (95\% CI: 5.07-9.13).

\section{Safety Profile of the 79 Elderly Patients with ES-SCLC Who Received Anlotinib Treatment}

All of the 79 elderly patients were available for safety profile.

The maximum toxicity of the 79 elderly patients that occurred during treatment with anlotinib were documented and analyzed. No grade 5 adverse reactions were noted during the entire treatment. As shown in Table 3, the common drug-related adverse reactions were hypertension (40.5\%), hand-foot syndrome (HFS) (31.6\%), diarrhea (27.8\%), decreased appetite (20.3\%), fatigue (17.7\%), weight loss (17.7\%), hematological toxicity (13.9\%), hypertriglyceridemia (11.4\%), AST/ALT elevation (8.9\%), dizziness $(6.3 \%)$ and hemoptysis (2.5\%). Importantly, most of the adverse reactions were grade $1-2$. The grade $\geq 3$ adverse reactions were observed in hypertension (11.4\%), HFS $(6.3 \%)$, diarrhea $(2.5 \%)$, fatigue $(3.8 \%)$, hematological 


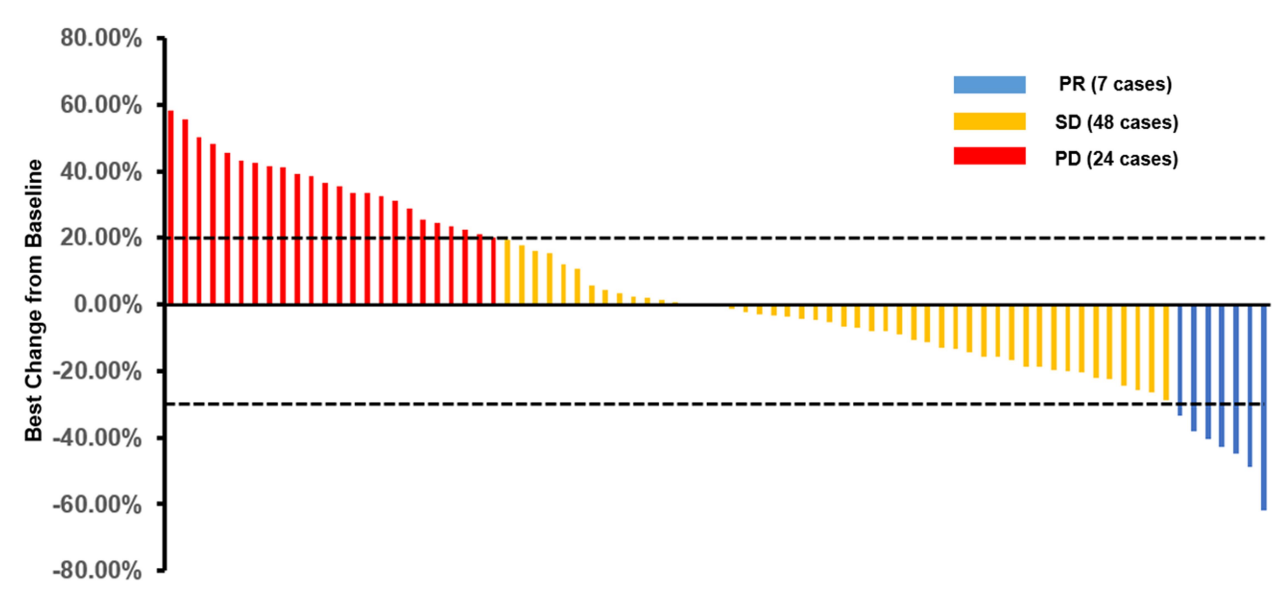

Figure 2 Waterfall plot for the best percentage change in target lesion size of the 79 elderly patients with previously treated extensive-stage small cell lung cancer.
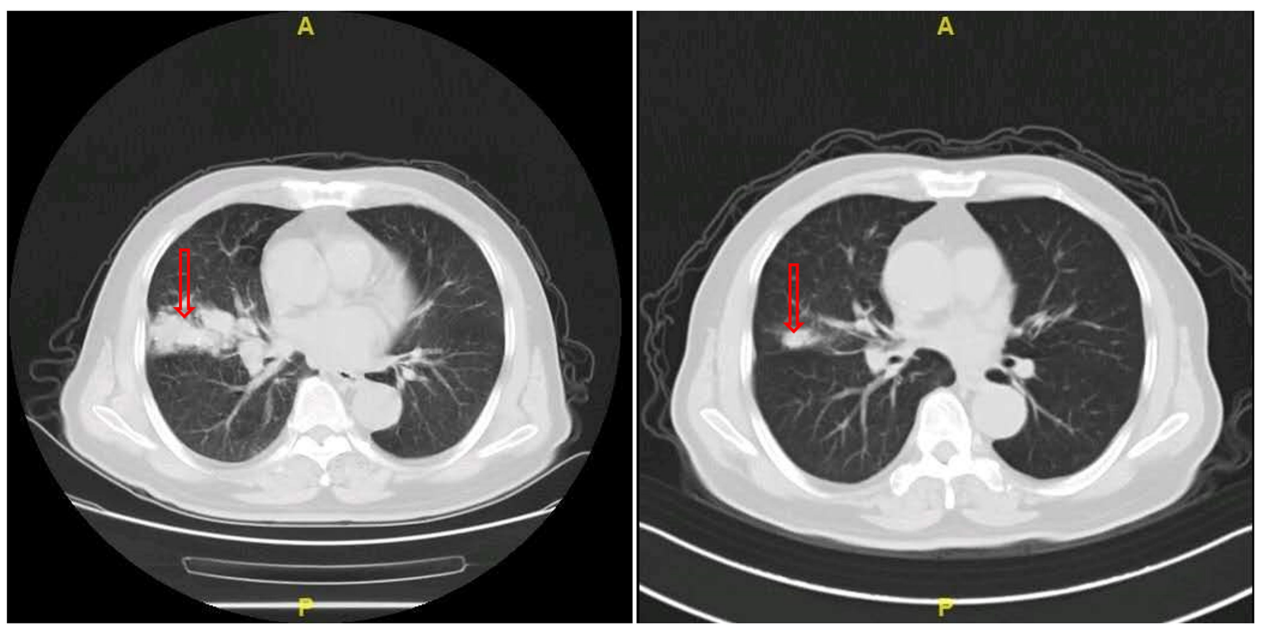

Figure 3 The CT scan results of the changes for primary target lesions in one patient with SCLC after 2 cycles of treatment with anlotinib.

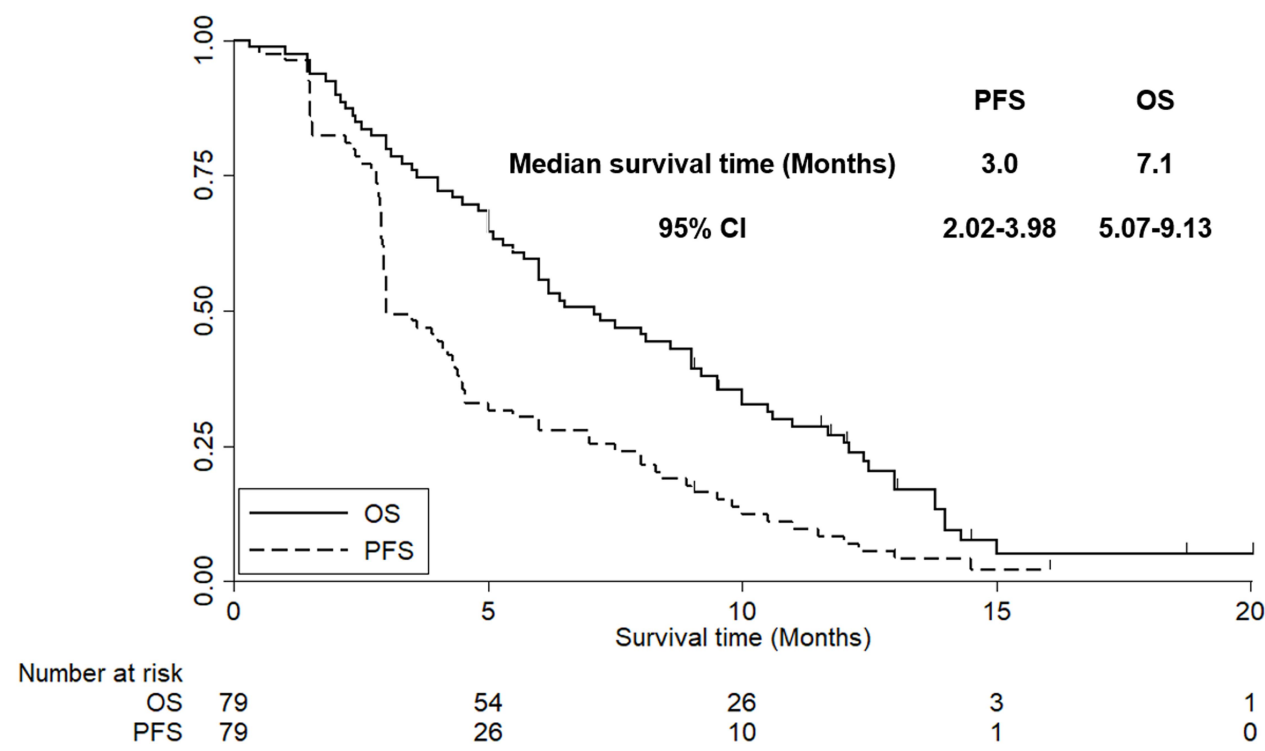

Figure 4 The progression-free survival and overall survival of the 79 elderly patients with previously treated extensive-stage small cell lung cancer. 
Table 2 Univariate analysis for PFS of the $\mathbf{7 9}$ elderly patients with ES-SCLC according to baseline characteristics subgroups

\begin{tabular}{|c|c|c|c|c|}
\hline Characteristics & $\mathbf{N}$ & $\begin{array}{l}\text { Median PFS } \\
\text { (Months) }\end{array}$ & $95 \% \mathrm{Cl}$ & $P$ \\
\hline Age (Years) & & & & 0.515 \\
\hline$<71$ & 37 & 3.5 & $2.15-4.85$ & \\
\hline$\geq 71$ & 42 & 2.8 & $2.01-3.59$ & \\
\hline Gender & & & & 0.436 \\
\hline Male & 56 & 2.7 & $1.92-3.48$ & \\
\hline Female & 23 & 3.6 & $2.23-4.97$ & \\
\hline ECOG score & & & & 0.019 \\
\hline $0-1$ & 42 & 4.1 & $2.56-5.64$ & \\
\hline 2 & 37 & 2.2 & $1.8 \mathrm{I}-2.59$ & \\
\hline Smoking status & & & & 0.616 \\
\hline Nonsmoker & 11 & 3.5 & $2.25-4.75$ & \\
\hline $\begin{array}{l}\text { Former smoker/ } \\
\text { smoker }\end{array}$ & 68 & 3.0 & $2.21-3.79$ & \\
\hline $\begin{array}{l}\text { Relapse type of first- } \\
\text { line regimen }\end{array}$ & & & & 0.095 \\
\hline Platinum-sensitive & 38 & 3.9 & $2.34-5.46$ & \\
\hline Platinum-resistant & 35 & 2.5 & $1.75-3.25$ & \\
\hline $\begin{array}{l}\text { Lines of previous } \\
\text { treatment }\end{array}$ & & & & 0.652 \\
\hline 2 & 43 & 3.0 & $1.97-4.03$ & \\
\hline$\geq 3$ & 36 & 2.8 & $1.88-3.72$ & \\
\hline $\begin{array}{l}\text { History of previous } \\
\text { radiotherapy }\end{array}$ & & & & 0.773 \\
\hline Yes & 53 & 3.0 & $2.13-3.87$ & \\
\hline No & 26 & 3.0 & $1.99-4.01$ & \\
\hline $\begin{array}{l}\text { History of targeted } \\
\text { drug therapy }\end{array}$ & & & & 0.731 \\
\hline Yes & 11 & 3.5 & $2.11-4.89$ & \\
\hline No & 68 & 3.0 & $1.91-4.09$ & \\
\hline $\begin{array}{l}\text { History of } \\
\text { immunotherapy }\end{array}$ & & & & 0.853 \\
\hline Yes & 10 & 3.7 & $2.06-5.34$ & \\
\hline No & 69 & 2.9 & $1.99-3.81$ & \\
\hline
\end{tabular}

Abbreviations: PFS, progression-free survival; ES-SCLC, extensive-stage small cell lung cancer; ECOG, Eastern Cooperative Oncology Group; $\mathrm{Cl}$, confidence interval.

toxicity (2.5\%) and AST/ALT elevation (1.3\%). A total of 9 patients exhibited more than grade 2 hypertension. Among them, only 2 patients $(2.5 \%)$ were grade 4 hypertension.

\section{The Prognostic Significance According to Hypertension and HFS Status}

Hypertension and HFS were the most common adverse reactions in this study. Consequently, the analysis of prognostic
Table 3 Safety profile of the 79 elderly patients with ES-SCLC who received anlotinib treatment

\begin{tabular}{|l|l|l|l|}
\hline Adverse Reactions & $\begin{array}{l}\text { Total } \\
\text { (N, \%) }\end{array}$ & $\begin{array}{l}\text { Grade I-2 } \\
\text { (N, \%) }\end{array}$ & $\begin{array}{l}\text { Grade } \geq \mathbf{3} \\
\text { (N, \%) }\end{array}$ \\
\hline Hypertension & $32(40.5)$ & $23(29.1)$ & $9(I I .4)$ \\
Hand-foot syndrome & $25(31.6)$ & $20(25.3)$ & $5(6.3)$ \\
Diarrhea & $22(27.8)$ & $20(25.3)$ & $2(2.5)$ \\
Decreased appetite & $16(20.3)$ & $16(20.3)$ & $0(0.0)$ \\
Fatigue & $14(17.7)$ & $1 \mathrm{II}(13.9)$ & $3(3.8)$ \\
Weight loss & $14(17.7)$ & $14(17.7)$ & $0(0.0)$ \\
Hematological toxicity & $1 \mathrm{I}(13.9)$ & $9(11.4)$ & $2(2.5)$ \\
Hypertriglyceridemia & $9(1 \mathrm{I} .4)$ & $9(11.4)$ & $0(0.0)$ \\
AST/ALT elevation & $7(8.9)$ & $6(7.6)$ & $\mathrm{I}(1.3)$ \\
Dizziness & $5(6.3)$ & $5(6.3)$ & $0(0.0)$ \\
Hemoptysis & $2(2.5)$ & $2(2.5)$ & $0(0.0)$ \\
\hline
\end{tabular}

Abbreviations: ES-SCLC, extensive-stage small cell lung cancer; AST, aspartate amino transferase; ALT, alanine aminotransferase.

significance was mainly focused on hypertension and HFS. As shown in Table 3, a total of 32 and 25 patients experienced hypertension and PFS during anlotinb treatment, respectively. The subsequent analysis regarding the prognostic significance according to hypertension and HFS was performed. Given that the baseline characteristics of the 79 elderly patients with ES-SCLC according to hypertension and HFS status were comparable, the PFS of the 79 patients according to hypertension and HFS status is illustrated in Figure 5. The median PFS of patients with hypertension was longer than that of patients with non-hypertension (4.35 vs 2.95 months, $\left.\chi^{2}=6.63, P=0.01\right)$. Similarly, the median PFS of patients with HFS was superior to that of patients with nonHFS (4.20 vs 2.95 months, $\chi^{2}=5.01, P=0.03$ ).

Furthermore, Cox regression model for PFS was performed including the baseline characteristics that were significant in univariate analysis as shown in Table 2 to adjust the confounding factors. Results of the multivariate analysis are illustrated in Table 4. Statistically significant difference was observed regarding the influence of hypertension status on PFS after multivariate adjustment. The results demonstrated that hypertension was an independent factor for PFS [Hazard Radio (HR $=0.68, P=0.031$ ). Besides, ECOG score was also an independent factor for PFS (HR=0.59, $P=0.023$ ). However, HFS status exhibited a marginal influence on PFS after multivariate adjustment $(\mathrm{HR}=0.73, P=0.062)$.

\section{Discussion}

To our knowledge, the present study was the first retrospective analysis that highlighted real-world evidence 

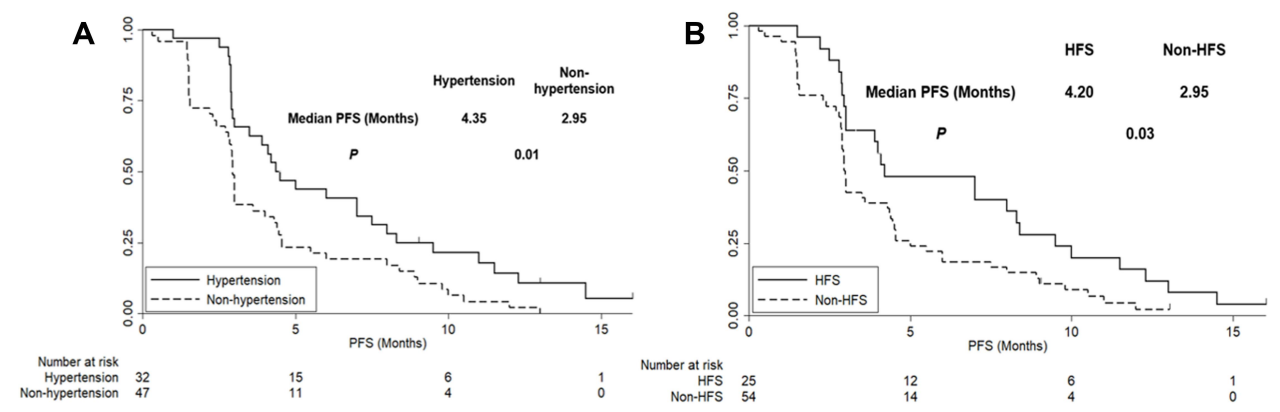

Figure $5(\mathbf{A}, \mathbf{B})$ The progression-free survival of the 79 elderly patients with previously treated extensive-stage small cell lung cancer according to hypertension and handfoot syndrome status.

regarding the efficacy and safety of anlotinib for elderly patients with previously treated ES-SCLC. Simultaneously, the prognostic significance according to hypertension and HFS status indicated that hypertension or HFS occurred during the treatment of anlotinib might confer superior prognosis. Anlotinib is effective and safe for elderly patients with previously treated ES-SCLC.

To our knowledge, the proportion of elderly patients is increasing in China and age is the most important risk factor for numerous cancers including SCLC. The decreases in lean body mass, hepatic blood flow and renal function that accompany aging was proven to influence drug distribution, metabolism and excretion. ${ }^{25}$ Consequently, elderly patients were always selected with caution and restriction on age was the primary exclusion criteria in considerable clinical trials. ${ }^{26}$ Furthermore, a previous survey that analyzed the clinical trials for cancer drug registration over 7 years indicated that a great disparity between the proportion of elderly patients in the total population and the proportion in clinical trials for lung cancer was observed and under-representation was especially notable for patients with $\geq 75$ years. ${ }^{27}$ Therefore, elderly patients were in absence of effective therapeutic regimens in both clinical trials and clinical practice.

Table 4 Multivariate Cox regression analysis for PFS according to baseline characteristic and hypertension and HFS status

\begin{tabular}{|l|l|l|l|}
\hline Characteristics & HR & $\mathbf{9 5 \%} \mathbf{C l}$ & $\mathbf{P}$ \\
\hline $\begin{array}{l}\text { ECOG } \\
0 \sim \text { I vs 2 }\end{array}$ & 0.59 & $0.31-0.93$ & 0.023 \\
\hline $\begin{array}{l}\text { Hypertension status } \\
\text { Hypertension vs Non-hypertension }\end{array}$ & 0.68 & $0.42-0.97$ & 0.031 \\
\hline $\begin{array}{l}\text { HFS status } \\
\text { HFS vs Non-HFS }\end{array}$ & 0.73 & $0.45-1.02$ & 0.062 \\
\hline
\end{tabular}

Abbreviations: ECOG, Eastern Cooperative Oncology Group; HR, hazard ratio; $\mathrm{Cl}$, confidence interval; HFS, hand-foot syndrome.
The regimen of platinum combined with etoposide chemotherapy was widely used as the gold standard treatment for SCLC in the past 30 years. Despite a high rate of response for this regimen, patients with SCLC always inevitably relapsed. ${ }^{28}$ Fortunately, a new landmark that FDA approved atezolizumab in combination with first-line platinum doublet chemotherapy for patients with ES-SCLC according to the Impower 133 clinical trial was noted in $2018 .{ }^{29}$ Topotecan was the only second-line drug approved for patients with ES-SCLC. Numerous studies demonstrated moderate efficacy and prognosis accompanied with considerable adverse reactions of topotecan treatment clinically. ${ }^{30}$ However, treatment as third-line or subsequentline for patients with ES-SCLC remained limited. ${ }^{31}$ Encouragingly, anlotinib is licensed for the treatment of NSCLC, ${ }^{32}$ SCLC $^{15}$ and soft tissue sarcoma in China currently. ${ }^{33}$

With regard to the efficacy of anlotinib in elderly patients with ES-SCLC, The ORR and DCR in our study was $8.9 \%$ and $69.6 \%$, respectively. The prognosis indicated that the median PFS was 3.0 months. The PFS of our study seemed to be slightly shorter than that of the phase II clinical trial of anlotinib for ES-SCLC initiated by Cheng Ying and colleagues (ORR $=4.9 \%, \mathrm{DCR}=71.6 \%$ median PFS=4.1 months of anlotinib group). ${ }^{15}$ We speculated that one reason could be attributed to the disparity of age between the two studies. The median age in ALTER1202 and our study was 57 and 71 years, respectively. A previous study exhibited that elderly patients had a trend for worse prognosis compared with the younger patients. ${ }^{34}$ Another explanation could be the retrospective design of our study. Management of the patients in retrospective study was not sufficient and normative compared with well-designed phase II clinical trial, which was proved in another retrospective study. ${ }^{35}$ Furthermore, it should be noted that the proportion of patients with 
ECOG 2 score in our study was much higher than that in ALTER1202 (46.8\% vs 4.9\%). To the best of our knowledge, ECOG score was one of the most important prognostic factors in SCLC and poor PS status was corrected with worse prognosis. ${ }^{36}$ Besides, the results of Cox regression analysis in our study demonstrated that patients with ECOG 2 score were associated with worse PFS. And the result was consistent with that of the previous study. ${ }^{37}$ Another phase II study of anlotinib in 45 patients with relapsed SCLC was reported recently. ORR, DCR, median PFS and median OS was $11 \%, 67 \%, 4.1$ months and 6.1 months, respectively. ${ }^{17}$ The subgroup analysis in their study regarding the patients with $\geq 65$ years suggested that the median PFS was 2.7 months, which was consistent with that in our study. Additionally, one retrospective analysis initiated by DF Chen and colleagues included 73 patients with ES-SCLC who received anlotinib treatment was reported recently. ${ }^{38}$ ORR, DCR and median PFS in their study was $15.1 \%, 74.0 \%$ and 2.6 months, respectively. The median PFS of the patients $\geq 65$ years in the subgroup analysis was 3.0 months, which was in concert with that of our study. However, ORR in their study was significantly higher. The explanation could be attributed to the fact that a portion of patients were treated with anlotinib as second-line therapy in their study. However, an obvious limitation of the retrospective study was that they failed to evaluate the OS owing to the relatively insufficient follow-up period. Given that the duration of followup was enough in our study, overall survival was also assessed. The median OS of the patients in our study was 7.1 months, which was similar to that reported in ALTER1202 trial (median OS=7.3 months). We speculated that the continued approval of immunotherapy drugs (PD-1 inhibitors) in China since the license of anlotinib in 2018 contributed to the survival benefit for the elderly patients as subsequent treatment. Pembrolizumab and nivolumab were proven to be effective for previously treated patients with ES-SCLC as subsequent-line therapy in KEYNOTE 028 and Checkmate 032 studies. ${ }^{8,9}$ Immunotherapy was available as the subsequent-line treatment for elderly patients with ES-SCLC to use after the progression of anlotinib in our study.

With regard to the safety profile, our study indicated that hypertension was the most common adverse reaction during anlotinib therapy, which was consistent with the adverse reactions of ALTER1202 study and the phase II clinical trial. However, it should be noted that the incidence of hypertension in our study was higher than that in the two prospective studies. We speculated that the explanation could be attributed to the older age in our study. To our knowledge, elderly patients always presented with medical and physiological characteristics which were susceptibility to hypertension. ${ }^{39}$ That could be the reason why the incidence of hypertension in elderly patients were higher when receiving anlotinib treatment. Besides, the other common adverse reactions were HFS, diarrhea, decreased appetite, fatigue, weight loss, hematological toxicity, AST/ALT elevation, dizziness and hemoptysis, which were consistent with those found in the ALTER1202 clinical trial. And no new adverse reactions were observed.

It was noteworthy that our study was the first research focusing on the association between PFS and adverse reactions during anlotinib treatment. The prognostic significance according to hypertension and HFS status in our study demonstrated that hypertension or HFS occurred during the treatment of anlotnib could be used as biomarkers to predict prognosis. And the result was in concert with that in the previous retrospective study of apatinib for patients with NSCLC. ${ }^{40,41}$ To our knowledge, hypertension and HFS were the common adverse reactions concomitant with the treatment of antiangiogenic inhibitors that targeted the VEGF pathway. Hypertension might be attributed to the mechanism that inhibition of VEGFR in vascular endothelial cells decreased the production of nitricoxide and prostacyclins, thus leading to increased blood pressure. ${ }^{42}$ HFS might be induced by decreased reconstruction of skin after restriction of vessels. ${ }^{43}$ Therefore, hypertension or HFS induced by anlotinib could partly reflect the inherent host biology that caused differences in VEGF/ VEGFR blockade. ${ }^{44}$ However, the conclusion that elderly patients with hypertension or HFS might confer superior prognosis should be validated in large-scale prospective trials and more active attempts should be used to control hypertension or HFS instead of reduction in drug dosing or interruption of the therapy when hypertension or HFS occurred during anlotinib treatment. ${ }^{45}$

Limitations inevitably existed in our study. Firstly, the sample size was small, only 79 subjects were enrolled. Secondly, the bias of the retrospective analysis could not be avoided. However, the prognostic significance according to hypertension and HFS status was interpreted thoroughly. We thought our study was of clinical significance for the prognosis evaluation of elderly patients with ESSCLC who received anlotinib treatment. 


\section{Conclusion}

This retrospective study indicated that the preliminary efficacy and safety of anlotinib in the treatment for elderly patients with previously treated ES-SCLC was satisfactory. Patients with hypertension and hand-foot syndrome might confer superior prognosis.

\section{Acknowledgments}

The authors would like to express our sincere gratitude to the elderly patients and their relatives for agreeing to participate in this work.

\section{Disclosure}

The authors declare that they have no conflicts of interest for this work.

\section{References}

1. Bray F, Ferlay J, Soerjomataram I, et al. Global cancer statistics 2018: GLOBOCAN estimates of incidence and mortality worldwide for 36 cancers in 185 countries. CA Cancer J Clin. 2018;68 (6):394-424. doi:10.3322/caac.21492.

2. Chen W, Zheng R, Baade PD, et al. Cancer statistics in China, 2015. CA Cancer J Clin. 2016;66(2):115-132. doi:10.3322/caac.21338.

3. Igawa $\mathrm{S}$, Ono $\mathrm{T}$, Kasajima $\mathrm{M}$, et al. Impact of amrubicin monotherapy as second-line chemotherapy on outcomes in elderly patients with relapsed extensive-disease small-cell lung cancer. Cancer Manag Res. 2020;12:4911-4921. doi:10.2147/cmar.s255552.

4. Tsoukalas N, Aravantinou-Fatorou E, Baxevanos P, et al. Advanced small cell lung cancer (SCLC): new challenges and new expectations. Ann Transl Med. 2018;6(8):145. doi:10.21037/atm.2018.03.31.

5. Yang $\mathrm{S}$, Zhang Z, Wang Q. Emerging therapies for small cell lung cancer. J Hematol Oncol. 2019;12(1):47. doi:10.1186/s13045-019-0736-3.

6. Poirier JT, George J, Owonikoko TK, et al. New approaches to SCLC therapy: from the laboratory to the clinic. $J$ Thorac Oncol. 2020;15 (4):520-540. doi:10.1016/j.jtho.2020.01.016.

7. Dómine M, Moran T, Isla D, et al. SEOM clinical guidelines for the treatment of small-cell lung cancer (SCLC) (2019). Clin Transl Oncol. 2020;22(2):245-255. doi:10.1007/s12094-020-02295-w.

8. Ott PA, Elez E, Hiret S, et al. Pembrolizumab in patients with extensive-stage small-cell lung cancer: results from the phase $\mathrm{Ib}$ KEYNOTE-028 study. J Clin Oncol. 2017;35(34):3823-3829. doi:10.1200/jco.2017.72.5069.

9. Antonia SJ, López-Martin JA, Bendell J, et al. Nivolumab alone and nivolumab plus ipilimumab in recurrent small-cell lung cancer (CheckMate 032): a multicentre, open-label, Phase 1/2 trial. Lancet Oncol. 2016;17(7):883-895. doi:10.1016/s1470-2045(16)30098-5.

10. Nowak-Sliwinska P, Alitalo K, Allen E, et al. Consensus guidelines for the use and interpretation of angiogenesis assays. Angiogenesis. 2018;21(3):425-532. doi:10.1007/s10456-018-9613-x.

11. Dowell JE, Amirkhan RH, Lai WS, et al. Survival in small cell lung cancer is independent of tumor expression of VEGF and COX-2. Anticancer Res. 2004;24(4):2367-2373.

12. Lu H, Jiang Z. Advances in antiangiogenic treatment of small-cell lung cancer. Onco Targets Ther. 2017;10:353-359. doi:10.2147/ott.s119714.

13. Tiseo M, Boni L, Ambrosio F, et al. Italian, multicenter, Phase III, randomized study of cisplatin plus etoposide with or without bevacizumab as first-line treatment in extensive-disease small-cell lung cancer: the GOIRC-AIFA FARM6PMFJM trial. $J$ Clin Oncol. 2017;35(12):1281-1287. doi:10.1200/jco.2016.69.4844.
14. Li H, Zeng J, Jin X, et al. Apatinib for chemotherapy-refractory extensive-stage SCLC: a retrospective study. Cancer Chemother Pharmacol. 2019;83(6):1083-1090. doi:10.1007/s00280-01903823-4.

15. Ying Cheng QW, Kai L, Li K, et al. OA13.03 anlotinib as third-line or further-line treatment in relapsed SCLC: a multicentre, randomized, double-blind Phase 2 trial. J Thorac Oncol. 2018;13(10): S351-S352. doi:10.1016/j.jtho.2018.08.308.

16. Wang S, Zimmermann S, Parikh K, et al. Current diagnosis and management of small-cell lung cancer. Mayo Clin Proc. 2019;94 (8):1599-1622. doi:10.1016/j.mayocp.2019.01.034.

17. Wu D, Nie J, Hu W, et al. A Phase II study of anlotinib in 45 patients with relapsed small cell lung cancer. Int J Cancer. 2020. doi:10.1002/ ijc.33161.

18. Chung HC, Piha-Paul SA, Lopez-Martin J, et al. Pembrolizumab after two or more lines of previous therapy in patients with recurrent or metastatic SCLC: results from the KEYNOTE-028 and KEYNOTE-158 studies. $J$ Thorac Oncol. 2020;15(4):618-627. doi:10.1016/j.jtho.2019.12.109.

19. Gitlitz BJ, Moon J, Glisson BS, et al. Sorafenib in platinum-treated patients with extensive stage small cell lung cancer: a Southwest oncology group (SWOG 0435) phase II trial. J Thorac Oncol. 2010;5(11):1835-1840. doi:10.1097/JTO.0b013e3181f0bd78.

20. Schneider BJ, Gadgeel SM, Ramnath N, et al. Phase II trial of sunitinib maintenance therapy after platinum-based chemotherapy in patients with extensive-stage small cell lung cancer. $J$ Thorac Oncol. 2011;6(6):1117-1120. doi:10.1097/JTO.0b013e31821529c3.

21. Liu X, Qin S, Wang Z, et al. Correction to: early presence of anti-angiogenesis-related adverse events as a potential biomarker of antitumor efficacy in metastatic gastric cancer patients treated with apatinib: a cohort study. J Hematol Oncol. 2018;11(1):5. doi:10.1186/ s13045-017-0545-5.

22. Eisenhauer EA, Therasse P, Bogaerts J, et al. New response evaluation criteria in solid tumours: revised RECIST guideline (version 1.1). Eur J Cancer. 2009;45(2):228-247. doi:10.1016/j.ejca.2008.10. 026 .

23. Miller TP, Fisher BT, Getz KD, et al. Unintended consequences of evolution of the common terminology criteria for adverse events. Pediatr Blood Cancer. 2019;66(7):e27747. doi:10.1002/pbc.27747.

24. Goodwin R, Ding K, Seymour L, et al. Treatment-emergent hypertension and outcomes in patients with advanced non-small-cell lung cancer receiving chemotherapy with or without the vascular endothelial growth factor receptor inhibitor cediranib: NCIC clinical trials group study BR24. Ann Oncol. 2010;21(11):2220-2226. doi:10.1093/ annonc/mdq221.

25. Fukuda M, Soda H, Soejima Y, et al. A Phase I trial of carboplatin and etoposide for elderly ( $>$ or $=75$ year-old) patients with small-cell lung cancer. Cancer Chemother Pharmacol. 2006;58(5):601-606. doi:10.1007/s00280-006-0188-7.

26. Yang Y, Sun N, Sun P, et al. Clinical characteristics and prognosis of elderly small cell lung cancer patients complicated with hyponatremia: a retrospective analysis. Anticancer Res. 2017;37(8):4681-4686. doi:10.21873/anticanres.11872.

27. Talarico L, Chen G, Pazdur R. Enrollment of elderly patients in clinical trials for cancer drug registration: a 7-year experience by the US food and drug administration. J Clin Oncol. 2004;22 (22):4626-4631. doi:10.1200/jco.2004.02.175.

28. Reck M, Horn L, Novello S, et al. Phase II study of roniciclib in combination with cisplatin/etoposide or carboplatin/etoposide as first-line therapy in patients with extensive-disease small cell lung cancer. $J$ Thorac Oncol. 2019;14(4):701-711. doi:10.1016/j. jtho.2019.01.010.

29. Horn L, Mansfield AS, Szczęsna A, et al. First-line atezolizumab plus chemotherapy in extensive-stage small-cell lung cancer. $N$ Engl J Med. 2018;379(23):2220-2229. doi:10.1056/NEJMoa1809064. 
30. Garst J. Topotecan: an evolving option in the treatment of relapsed small cell lung cancer. Ther Clin Risk Manag. 2007;3(6):1087-1095.

31. de Jong WK, Ten Hacken NH, Groen HJ. Third-line chemotherapy for small cell lung cancer. Lung Cancer. 2006;52(3):339-342. doi:10.1016/j.lungcan.2006.02.005.

32. Han B, Li K, Wang Q, et al. Effect of anlotinib as a third-line or further treatment on overall survival of patients with advanced non-small cell lung cancer: the ALTER 0303 Phase 3 randomized clinical trial. JAMA Oncol. 2018;4(11):1569-1575. doi:10.1001/ jamaoncol.2018.3039.

33. Chi Y, Fang Z, Hong X, et al. Safety and efficacy of anlotinib, a multikinase angiogenesis inhibitor, in patients with refractory metastatic soft-tissue sarcoma. Clin Cancer Res. 2018;24(21):5233-5238. doi:10.1158/1078-0432.ccr-17-3766.

34. Li J, Chen P, Dai CH, et al. Outcome and treatment in elderly patients with small cell lung cancer: a retrospective study. Geriatr Gerontol Int. 2009;9(2):172-182. doi:10.1111/j.1447-0594.2009.00525.x.

35. Zhang $\mathrm{K}$, Ma X, Gao H, et al. Efficacy and safety of anlotinib in advanced non-small cell lung cancer: a real-world study. Cancer Manag Res. 2020;12:3409-3417. doi:10.2147/cmar.s246000.

36. Bremnes RM, Sundstrom S, Aasebø U, et al. The value of prognostic factors in small cell lung cancer: results from a randomised multicenter study with minimum 5 year follow-up. Lung Cancer. 2003;39 (3):303-313. doi:10.1016/s0169-5002(02)00508-1.

37. Liu JY, Zhu BR, Wang YD, et al. The efficacy and safety of Apatinib mesylate in the treatment of metastatic osteosarcoma patients who progressed after standard therapy and the VEGFR2 gene polymorphism analysis. Int J Clin Oncol. 2020;25(6):1195-1205. doi:10.1007/ s10147-020-01644-7.

38. Chen $\mathrm{D}, \mathrm{Xu}$ J, Zhao Y, et al. Prognostic value of tumor cavitation in extensive-stage small-cell lung cancer patients treated with anlotinib. J Cancer Res Clin Oncol. 2020;146(2):401-406. doi:10.1007/ s00432-019-03064-1.
39. Wang J, Ma JJ, Liu J, et al. Prevalence and risk factors of comorbidities among hypertensive patients in China. Int J Med Sci. 2017;14 (3):201-212. doi:10.7150/ijms.16974.

40. Fang SC, Huang W, Zhang YM, et al. Hypertension as a predictive biomarker in patients with advanced non-small-cell lung cancer treated with apatinib. Onco Targets Ther. 2019;12:985-992. doi:10.2147/ ott.s189984.

41. Liu X, Qin S, Wang Z, et al. Early presence of anti-angiogenesisrelated adverse events as a potential biomarker of antitumor efficacy in metastatic gastric cancer patients treated with apatinib: a cohort study. J Hematol Oncol. 2017;10(1):153. doi:10.1186/s13045-0170521-0.

42. Tang JR, Markham NE, Lin YJ, et al. Inhaled nitric oxide attenuates pulmonary hypertension and improves lung growth in infant rats after neonatal treatment with a VEGF receptor inhibitor. Am J Physiol Lung Cell Mol Physiol. 2004;287(2):L344-351. doi:10.1152/ ajplung.00291.2003.

43. Fischer A, Wu S, Ho AL, et al. The risk of hand-foot skin reaction to axitinib, a novel VEGF inhibitor: a systematic review of literature and meta-analysis. Invest New Drugs. 2013;31(3):787-797. doi:10.1007/s10637-013-9927-x.

44. Lankhorst S, Kappers MH, van Esch JH, et al. Mechanism of hypertension and proteinuria during angiogenesis inhibition: evolving role of endothelin-1. J Hypertens. 2013;31(3):444-454. doi:10.1097/ HJH.0b013e32835c1d1b.

45. Aparicio-Gallego G, Afonso-Afonso FJ, León-Mateos L, et al. Molecular basis of hypertension side effects induced by sunitinib. Anticancer Drugs. 2011;22(1):1-8. doi:10.1097/CAD.0b013e328340 3806.

\section{Publish your work in this journal}

Cancer Management and Research is an international, peer-reviewed open access journal focusing on cancer research and the optimal use of preventative and integrated treatment interventions to achieve improved outcomes, enhanced survival and quality of life for the cancer patient.
The manuscript management system is completely online and includes a very quick and fair peer-review system, which is all easy to use. Visit http://www.dovepress.com/testimonials.php to read real quotes from published authors. 